\title{
A small collection of mysids (Crustacea: Mysidacea) from the Dampier Archipelago, Western Australia
}

\author{
Yukio Hanamura \\ National Research Institute of Fisheries and Environment of Inland Sea, Maruish 2-17-5, \\ Hatsukaichi, Hiroshima Prefecture 739-0452, Japan. \\ email: hanamura(to affrc.go.jp

\begin{abstract}
During the faunal survey in the Dampier Archipelago, Western Australia, from 1998-2002, two species of mysid crustaceans, Siriella hanseni W. M. Tattersall, 1922 and Heteromysis harpaxoides Bäcescu and Bruce, 1980, were collected from the shallow coastal waters of the archipelago. The present collections of $S$. hanseni and $H$. harpaxoides are the fifth and the third records of their occurrences, respectively.
\end{abstract}

\section{INTRODUCTION}

The faunal survey of the Dampier Archipelago, Western Australia, was conducted by the Western Australian Museum from 1998-2002. The survey produced several mysid specimens from the shallow coastal waters of the archipelago, which were identified to the following two species: Siriella hanseni W. M. Tattersall, 1922 and Heteromysis harpaxoides Bäcescu and Bruce, 1980. Siriella hanseni has been recorded from the tropical coastal waters of the Indo-West Pacific, based mostly on damaged or juvenile specimens. Its occurrence in the Dampier Archipelago is the fifth record of this species and is also a new Western Australian record. The original description of $H$. harpaxoides was based on five specimens from Wistari Reef in the Great Barrier Reef, Queensland, and an additional single male specimen was collected from Ashmore Reef in Western Australia. Heteromysis harpaxoides has been found in association with the hermit crab genus Dardanus. The present collection is the third record of occurrence of this species and also provides a new habitat record.

\section{MATERIALS AND METHODS}

Total length ( $\mathrm{t}$ in millimeters) measured from the rostral plate to the posterior end of the telson, excluding apical spines, is used to represent the body size; ovig. for ovigerous; stn for station. Specimens treated in this study are deposited in the Western Australian Museum, Perth (WAM).

\section{SYSTEMATICS}

Siriella hanseni W. M. Tattersall, 1922

Figure 1
Siriella hanseni W. M. Tattersall, 1922: 448, figs 1, 2. - O. Tattersall, 1960: 167. - Ii, 1964: 577. - Pillai, 1965: 1689, fig. 11. - Bãcescu, 1986: 19. - Müller, 1993, 47. - Murano, 1998: 46. - Keable et al., 2003: 467.

\section{Material examined}

Western Australia, Dampier Archipelago. WAM C 29369 (2 males, $\mathrm{tl} \sim 7.5 \mathrm{~mm}$ [damaged]; 2 ovig. females, tl $\sim 7.5 \mathrm{~mm}$ [damaged]), stn DA3/99/51, Enderby I. $\left(20^{\circ} 35.20^{\prime} \mathrm{S}, 116^{\circ} 30.91^{\prime} \mathrm{E}\right)$, intertidal, off seaweed, coll. M. Hewitt, 01.09.1999.

\section{Description}

Carapace (Figure 1a) without process or tubercles on dorsal surface; posterior margin excavate, leaving last 2 thoracic somites uncovered in dorsal aspect; cervical sulcus distinct. Rostral plate (Figure 1 b) broadly rounded; pseudorostral process sharp, extending beyond end of rostral plate.

Abdomen (Figure 1a) smooth, without folds or spines; first to fifth somites subequal in length, sixth somite about 1.5 times as long as fifth.

Telson (Figure 1c) short, falling far short of distal suture of uropodal exopod, subequal in length to sixth abdominal somites, twice or slightly less than 2 times as long as basal width; posterior margin broadly rounded, with 3 short spines and 1 pair of long plumose setae; lateral margin weakly concave at basal two-fifths, armed with 3 anterior spines, followed by unarmed part, and with 14-16 spines posteriorly, increasing in length distally.

Eyes (Figure la, b) normal, cornea nearly as broad as ocular peduncle. Antennular peduncle in females (Figure 1b) with first segment longest, 3.5 times as long as second, third segment about 0.6 times as long as first; antennular peduncle in male more robust than in female, first segment 3.5 times as long as second, 


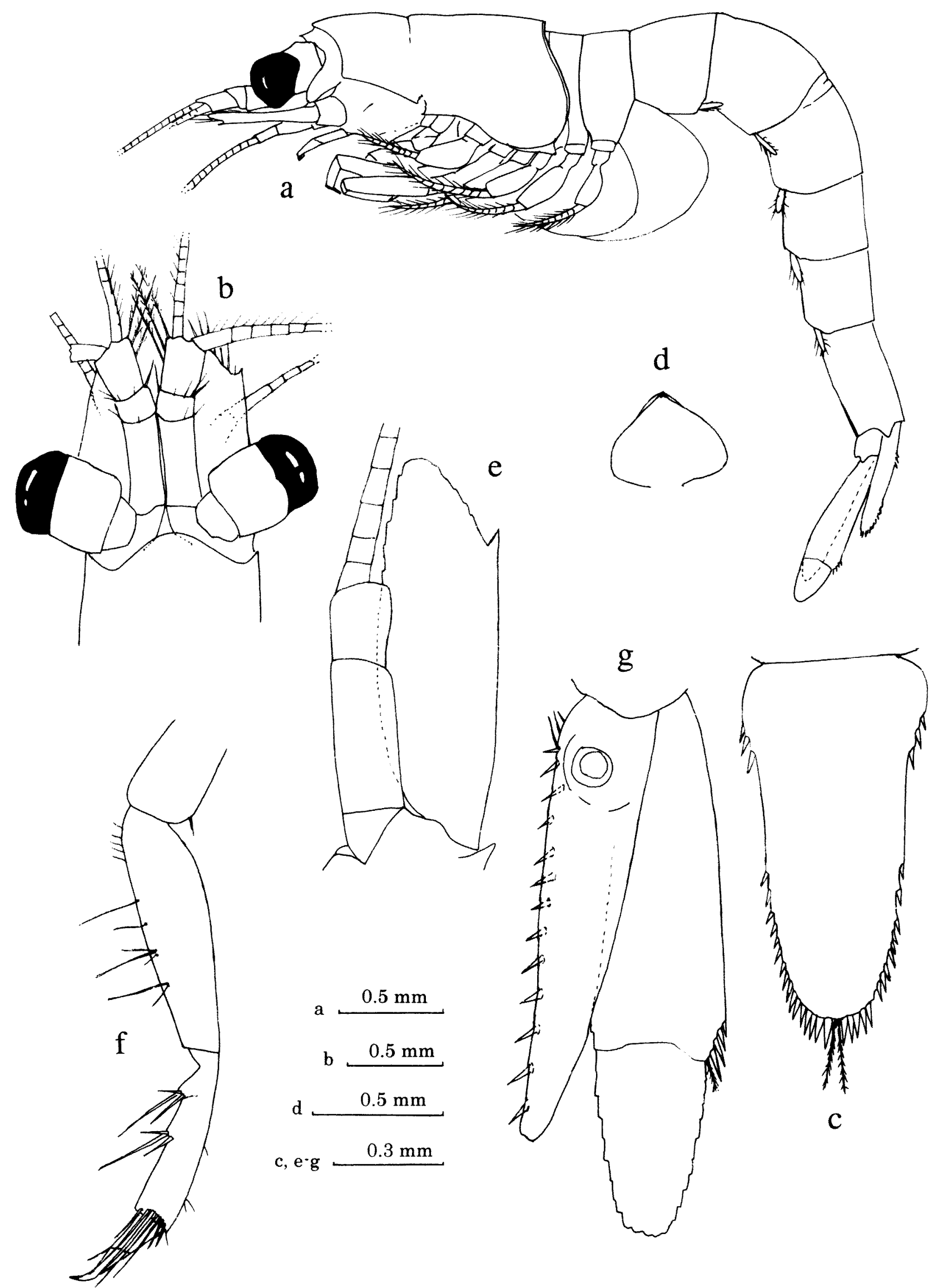

Figure 1 Siriella hanseni, W. M. Tattersall, 1922. a, ovig. female $(\mathrm{tl} \sim 7.5 \mathrm{~mm}) ; \mathbf{b}, \mathbf{d}, \mathbf{f}$, female $(\mathrm{tl} \sim 7.5 \mathrm{~mm})$; $\mathbf{c}, \mathbf{e}, \mathbf{g}$, male $(\mathrm{tl} \sim 7.5 \mathrm{~mm})$. a, entire body, lateral; $\mathbf{b}$, anterior part of carapace and cephalic appendages, dorsal; $\mathbf{c}$, telson, dorsal; d, labrum, external; e, right antenna, ventral; $f$, left 4 th thoracic endopod, mesial; $g$, right uropod, dorsal. 
third segment almost as long as combined length of basal 2 segments; male lobe well developed. Antennal scale (Figure $1 \mathrm{~b}$, e) falling slightly short of distal end of antennular peduncle, $3.0-3.5$ times as long as wide, relatively wider in females than in males; lateral spine situated at distal one-fifth; distal lobe almost as long as broad; suture separating terminal lobe indistinct. Labrum (Figure 1d) subtriangular, with minute spine at anteromedian margin.

Third thoracic endopod with ischium undivided, without distinct articulation; carpopropodus undivided into subsegments by distinct articulation, but with shallow, discontinuous suture near proximoventral setae running towards obliquely dorsal; dactylus strong, longer than tuft of terminal setae of carpopropodus. Dactylus of posterior 5 thoracic endopods (Figure 1f) small, nail with sharp terminal bend.

Pleopods in male biramous; pseudobranchial lobe on first and fifth pleopods straight; pseudobranchial lobes on second to fourth pleopods spirally-coiled, neither ramous with modified terminal setae. Female pleopods (Figure 1a) rudimentary, unsegmented lobe.

Exopod of uropod (Figure $1 \mathrm{~g}$ ) distinctly longer than endopod, proximal segment with 3 or 4 lateral spines near distal articulation and no plumose setae except for apical pair; endopod with 12 or 13 widely placed stout spines along mesioventral margin.

\section{Remarks}

Siriella hanseni is similar to the following five Indo-West Pacific species, which are characterized in having a proportionately short telson: $S$. brevicaudata Paulson, 1875, from the Indian Ocean; S. vincenti W. M. Tattersall, 1927, from southern Australia; S. lingvula Ii, 1964, from the northwestern Pacific; $S$. intermedia Panampunnayil, 1981, from the Laccadive Archipelago, Indian Ocean; and S. spinula Panampunnayil, 1995, from the southwest coast of Australia.

Siriella brevicaudata is distinguished from the aforementioned species by the possession of a subquadrate telson bearing a truncated or weakly concave apex. Siriella vincenti and S. spinula have a slightly pronounced, sub-triangular rostrum, opposed to an evenly rounded one in S. hanseni. The Pacific congener, $S$. lingvura, differs from $S$. hanseni in having the antennal scale with a distinct suture separating the terminal lobe, as opposed to having no suture in this species. Siriella intermedia possesses as many as 12 spines on the lateral margin of the uropodal exopod instead of having at most five in all other species.

Murano (1998) noted a minor discrepancy between a specimen of Siriella hanseni from the Arabian Gulf and the type specimen(s) from India. The telson of the former specimen has a longer un- naked part and also the distal end is more broadly rounded with a weak apical concavity, as well as a greater number of spines in the uropod. Specimens from the Dampier Archipelago possess a greater number of spines in the telson as compared with those of the type material as well as the specimen from the Arabian Gulf. In most other respects, however, the present specimens showed general agreement with the original description.

Bacescu (1986) reported the occurrence of several adult specimens of Siriella hanseni from northern Australia, but no account on their morphology was presented. Although there remains some uncertainty for the taxonomy of some local populations, future study may clarify their taxonomic status.

The majority of species belonging to the genus Siriella have a long frontal process on the labrum. The present specimens referred to Siriella hanseni are remarkable in having no such prominent process but have a microscopically small projection, a feature shared by $S$. lingvula and $S$. spinula. Panampunnayil (1995, Table 2) pointed out that $S$. hanseni and $S$. vincenti possess a long spine on the labrum. As far as I am aware, however, no reliable evidence that supports this account could be found in published documents (see also li, 1964). From their general morphological resemblance, it is highly possible that $S$. brevicaudata, $S$. vincenti, and $S$. intermedia have a similar frontal process on the labrum. Further studies are required and the taxonomic significance of the character states of these species should be re-evaluated.

\section{Habitat}

Shallow coastal waters, occurring often in association with sea grasses.

\section{Distribution}

Arabian Gulf (Murano, 1998), Gulf of Mannar, India (W. M. Tattersall, 1922), Singapore Strait (O. Tattersall, 1960), Darwin Harbour, northern Australia (Băcescu, 1986).

\section{Heteromysis harpaxoides Băcescu and Bruce, 1980} Figure 2

Heteromysis harpaxoides Bacescu and Bruce, 1980: 68, figs 2m-n, 3a-h. - Müller, 1993: 270.

Heteromysis (Gnathomysis) harpaxoides. Murano, 1988: 41. - Keable et al., 2003: 446.

Heteromysis harpaxoides. - Müller, 1993:270.

\section{Material examined}

WAM C 26023 (1 ovig. female, $\mathrm{t} 5.8 \mathrm{~mm}$ ), stn DA2/99/76, Goodwyn 1. $(2032.11 \mathrm{~S}, 11631.55 \mathrm{E}$ to $\left.20^{\circ} 32.40^{\prime} \mathrm{S}, 11631.22 \mathrm{E}\right), 13-15 \mathrm{~m}$, coll. S. SlackSmith and M. Hewitt, 25.07.1999. 


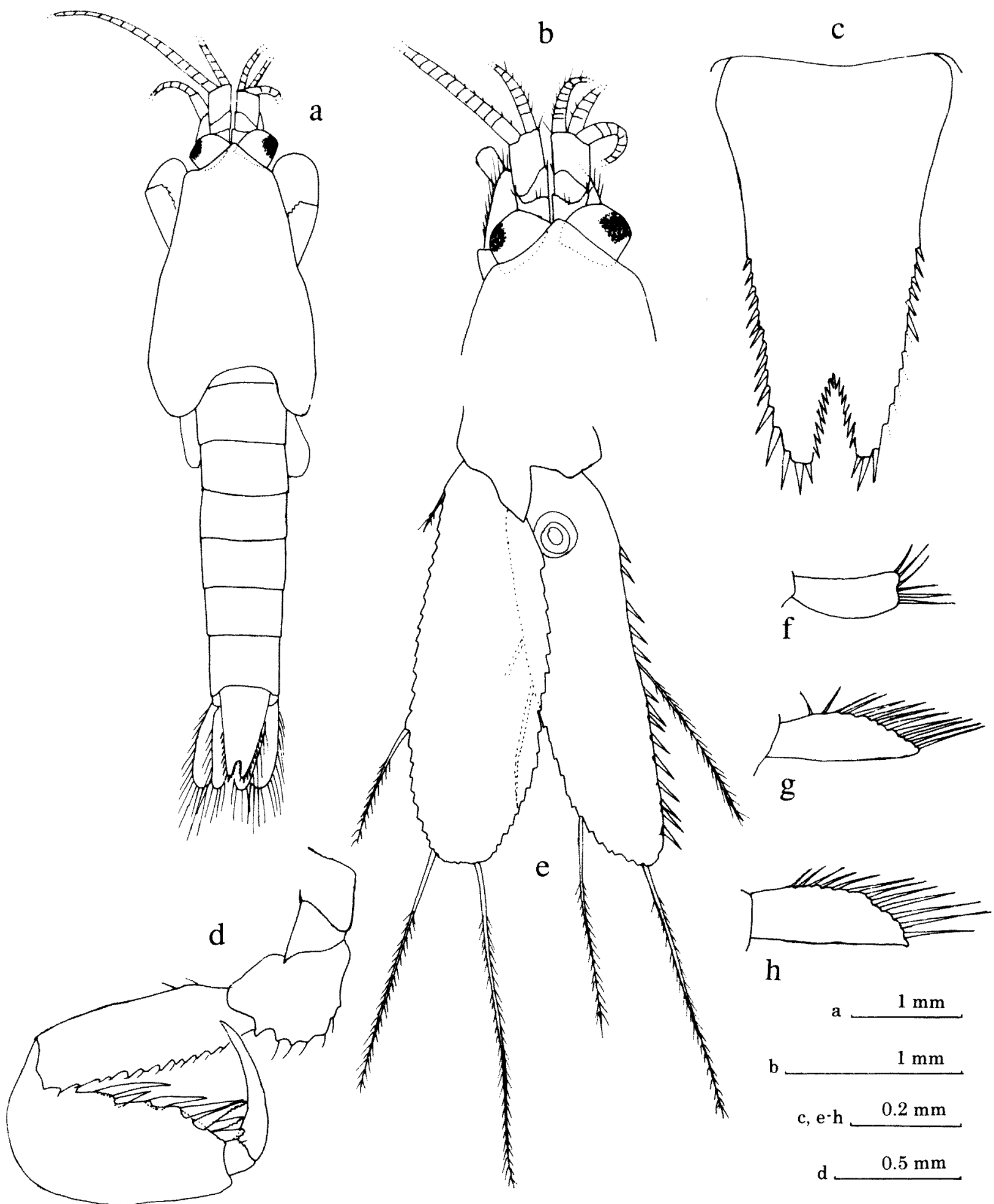

Figure 2 Heteromysis harpaxoides, ovig. female (tl $5.8 \mathrm{~mm}$ ). a, entire body dorsal; $\mathbf{b}$, anterior part of carapace and cephalic appendages, dorsal; $\mathrm{c}$, telson, dorsal; $\mathrm{d}$, right $3 \mathrm{rd}$ thoracic endopod, mesial; e, right uropod, ventral; $\mathrm{f}-\mathrm{h}$, left 1 st, 4 th, and 5 th pleopods.

\section{Description}

Body (Figure 2a) somewhat fragile. Rostrum (Figure 2a, b) triangular, with slightly obtuse apex; lateral margin nearly straight. Carapace (Figure 2a) well developed, covering almost entire part of cephalothorax; dorsal surface without tubercles, cervical sulcus barely visible; posterior margin excavate in dorsal view.
Abdomen (Figure 2a) smooth, without folds, spines, or processes; ventral surface smooth: percent length ratio of abdominal somites from first to sixth; $19.7: 17.9: 15.3: 15.3: 14.8: 17.0(=100)$.

Telson (Figure 2c) triangular with incised apex, 1.74 times as long as sixth abdominal somite, 1.83 times as long as broad; lateral margin basally naked, posterior half armed with 13 or 14 spines; posterior 
lobe with 2 apical spines, outer spines longer than inner pair; distal incision 0.38 times length of telson, armed with about 15 spinules on entire margin.

Eyes (Figure 2b) slightly depressed, cornea small, narrower than eyestalk. Antennule (Figure 2b) moderately robust, first peduncular segment with distolateral prolongation bearing some short setae distally; second segment of peduncle shortest, obliquely articulated with third segment, long seta present at distomesial corner; third segment with 2 setae at distomesial corner near base of inner antennular flagellum. Antennal scale elliptical, long, reaching midlength of distal segment of antennular peduncle, setose all around margin; antennal peduncle slightly extending beyond end of antennular peduncle.

Third thoracopod (Figure $2 \mathrm{~d}$ ) with stout endopod; ischium triangular, with lamellate projection bearing several large, flagellate denticles on mesial margin; merus longest, ventromesial margin armed with numerous, moderately large flagellated denticles along entire margin, ventrolateral margin bearing numerous, small denticles along entire length and 1 seta near basal one-third not seen in mesial view), dorsal margin with 2 setae near base; carpopropodus massive, ventrally armed with about 7 large spines, anterior 4 of which serrated anteriorly; dactylus sharp and strong.

Pleopods (Figure 2d-f) in female rudimentary, forming an unsegmented lobe; first pleopod with several setae on distal margin; second and third pleopods similar in shape, each with many setae along lateral margin. Uropod (Figure $2 \mathrm{~g}$ ) extending slightly beyond telson; endopod slightly longer than exopod, armed with about 14 spines along mesial margin.

\section{Remarks}

The present specimens agree well with the original description by Bácescu and Bruce (1980). Heteromysis harpaxoides is similar to H. stellata Bacescu and Bruce, 1980, recorded from Heron Island, Queensland. The former species can be distinguished only by the absence of stellate tubercles on the anterior surface of the carapace.

\section{Habitat}

Known to be commensal with pagurid hermit crabs, Dardanus sp. (?spp), but no evidence of association was obtained for the present specimen.

\section{Distribution}

Recorded only in Australia: Wistari Reef, Great Barrier Reef, Queensland (Bacescu and Bruce 1980); Ashmore Reef, Western Australia (Murano, 1988).

\section{ACKNOWLEDGEMENTS}

I am grateful to Masaaki Murano for his kind reading of an early version of the manuscript and also useful information on Sirie/la. I also thank Diana Jones and Melissa Hewitt for making available these interesting specimens of mysids for this study.

\section{REFERENCES}

Bacescu, M. (1986). Two new species of Heteroms sis from the coral reefs of northern Australia. Travaux du Museum National d'Histoire' Naturelle" "Grigore" Antipal" 28: 19-24.

Bacescu, M. and Bruce, A.J. (1980). New contributions to the knowledge of the representatives of genus Heteromysis s. I. from the Australian coral reefs. Travaux du Muséum National d'Histoire Naturelle "Grigore Antipa", 21: 63-72.

Ii, N. (1964). Mysidacea (Crustacea). Fauna Japonica. Biogeographical Society of Japan. $610 \mathrm{pp}$.

Keable, S.I., Fenton, G.F and Lowry, J.K. (2003). Mysidacea. In Lowry, I.K. and Stoddart, H.E. (eds), Crustacea: Malacostraca: Peracarida: Amphipoda, Cumacea, Mysidacea 19.2B: 419-471. Melbourne: CSIRO Publishing, Australia. pp xii +531.

Müller, H.-G. (1993). World Catologue and Bibliography of the Recent Mysidacea. Laboratory for Tropical Ecosystems Research and Information Service, Wetzlar. 491 pp.

Murano, M. (1988). Heteromysids (Crustacea; Mysidacea) from northern Australia with description of six new species. The Beagle, Records of the Northern Territory Museum of Arts and Sciences 5: 27-50.

Murano, M. (1998). Mysidae (Crustacea: Mysidacea) collected from the western Arabian Gulf. Planktom Biology and Ecology 45: 45-54.

Panampunnavil, S.U. (1981). On two new species of Siriella. Mahasagar, Bulletin of the National Institute of Octanography 14: 87-90.

Panampunnayil, S.U. (1995). Two new species of Siriellat (Crustacea-Mvsidacea) from the southwest coast of Australia. foumal of Plankton Research 17: 19391950 .

Paulson, O. (1875). Crustacea mari Rubri. Kiev 1: 123137. pls. 20. (not seen)

Pillai, N.K. (1965). A review of the work on the shallow water Mysidaced of the Indian waters. Proceedings of the Simposiam on Crustacea. Marine Biological Association of India 5: 1681-1728

Tattersall, O.S. (1960). Report on a small collection of Mysidacea from Singapere waters. Proceedings of the Zoological Societs of london 135: 165-181.

Tattersall, W.M. (1922). Indian Misidaced. Records of the Indian Mustum 24: $4+5-5(1)$

Tattersall, W.M. (1927). Australian opossum shrimps (Mvidatea). Records of the Australian Museam 3: $235-257$ 